\title{
Ebookshelf
}

\author{
Amanda Chiplock, Column Editor
}

\section{A Review of OvidSP as an E-books Delivery Platform}

\section{Peace Ossom Williamson}

\begin{abstract}
Books@Ovid is a database of full-text access to high-quality textbooks, manuals, and handbooks. These resources are largely practical in nature and cover a large variety of subjects in health professions including medicine, nursing, dentistry, chiropractic, and allied health fields. Topics of materials can include skills, pharmacology, anatomy, and patient education. Institutions that subscribe to Books@Ovid are able to use it via the OvidSP search platform, which allows for searching across databases provided by Ovid Technologies, Inc. Searching and browsing options as well as their implications for users will be explored in this review.
\end{abstract}

KEYWORDS. electronic books, electronic publishing, health sciences, Ovid, product review, databases
AUTHOR. Peace Ossom Williamson, MLS, MS, AHIP (peace@uta.edu) is Health
Sciences Librarian, Central Library, University of Texas at Arlington, 702 Planetarium
Place, Arlington, TX 76019.
This is an electronic version of an article published in Ossom Williamson, P. (2015). "A review of OvidSP as an e-books delivery platform,” Journal of Electronic Resources in Medical Libraries, 12(1), 48-58. Journal of Electronic Resources in Medical Libraries is available online at: http://www.tandfonline.com/doi/full/10.1080/15424065.2015.1001963




\section{INTRODUCTION}

Books@Ovid is one of the largest sources of health sciences texts in an online platform. The database is owned by Ovid Technologies, Inc. and contains resources such as Doody’s Premier Titles collections, Lippincott Williams \& Wilkins collections, and e-books from Wiley-Blackwell and Springer Publishing collections. Also included is the Joanna Briggs Institute online evidence-based practice book series. Furthermore, the number of e-books being offered is growing regularly. ${ }^{1}$ The books included in Books@Ovid cover a wide range of topics - e.g., behavioral and social sciences; life sciences and medical humanities; nursing; public health; many aspects of medicine, including obstetrics and gynecology, surgery, anesthesiology, and toxicology; and other health professions, including nursing, chiropractic, optometry, physical therapy. Within these fields, the e-books focus on various aspects of practice, such as skills, procedures, and patient education, while the majority of content is applied information of textbooks, handbooks, and manuals.

Books@Ovid is part of the OvidSP interface which searches any of the institution’s other journal and database subscriptions in one place, which makes it easier for users to find the content they need without knowing exactly where that content is housed. In addition to the e-book collections, institutions can also choose to purchase subscriptions to individual books. This allows for some customization and for an increase in the amount of access an institution has according to what its particular needs are. In addition, with a subscription, institutions will have access to the latest edition of the e-book, rather than having to purchase a new subscription each time.

This is an electronic version of an article published in Ossom Williamson, P. (2015). “A review of OvidSP as an e-books delivery platform,” Journal of Electronic Resources in Medical Libraries, 12(1), 48-58. Journal of Electronic Resources in Medical Libraries is available online at: http://www.tandfonline.com/doi/full/10.1080/15424065.2015.1001963 


\section{UTILIZING OVIDSP TO ACCESS BOOKS@OVID}

OvidSP access is convenient for several reasons, but there are downsides to the method of authentication. The first reason is that it allows for IP authentication, which means that any time users are on the campus of their institutions, they will not have to login. They can instantly access the resources through that interface. In addition, institutions who use proxy authentication can allow off-campus or off-site users to login to a proxy that virtually assigns them proxy access. Each user maintains their own proxy login information, which, for most institutions is unified with other login accounts such as email and work programs. This functionality is highly preferable over access code logins, which are more work for individual users and librarians alike. The downside to the method of authentication is that institutions are provided a password for access to which the IP addresses are mapped. This can be an issue because it can be difficult differentiating the authentication account from a personal account. One option for doing so is hiding the information showing the authentication account logged in information at the top. The second reason is that OvidSP does not require digital rights management software, which would allow for Ovid Technologies’ control of the use of its content.

OvidSP supports the latest edition of browsers that are currently highly used. At the moment, those browsers include the latest versions of Microsoft Internet Explorer, Mozilla Firefox, Google Chrome, and Apple Safari. Although there are a lot of positives to be said about OvidSP, there is also a missing feature: OvidSP is not optimized for use with mobile devices. According to the Ovid Technologies marketing team, OvidSP works best on devices 
with a screen size of 7 inches or above, but a 10 inch or greater screen is the most optimal. As mobile devices are becoming more used than traditional personal desktop and laptop computers, ${ }^{2-3}$ it would be advantageous of Ovid Technologies to adapt this interface to the mobile market.

\section{BROWSING FOR E-BOOKS}

Within OvidSP, users can choose to either search for resources or to browse. In order to browse e-books, the user can click over from the default selection of the Search tab over to the Books tab. The browsing screen is convenient in location and laid out in a simple and easy-to-understand manner, see Figure 1. Initially, the user is presented with all of the ebooks to which his or her institution has subscribed. On the left menu are options for performing a quick search or for browsing. Searches in the quick search bar may be keywords, titles, or authors. Ovid's natural language search pinpoints the field that the user is most likely searching and presents a list of relevance ranked results. These results can then be filtered by relevancy using a star system, publication date or type, and subject matter. Users can also use many of the browsing features including browsing by the first letter or number of the book titles, or browsing by subject or one of its subcategories.

This is an electronic version of an article published in Ossom Williamson, P. (2015). "A review of OvidSP as an e-books delivery platform,” Journal of Electronic Resources in Medical Libraries, 12(1), 48-58. Journal of Electronic Resources in Medical Libraries is available online at: http://www.tandfonline.com/doi/full/10.1080/15424065.2015.1001963 


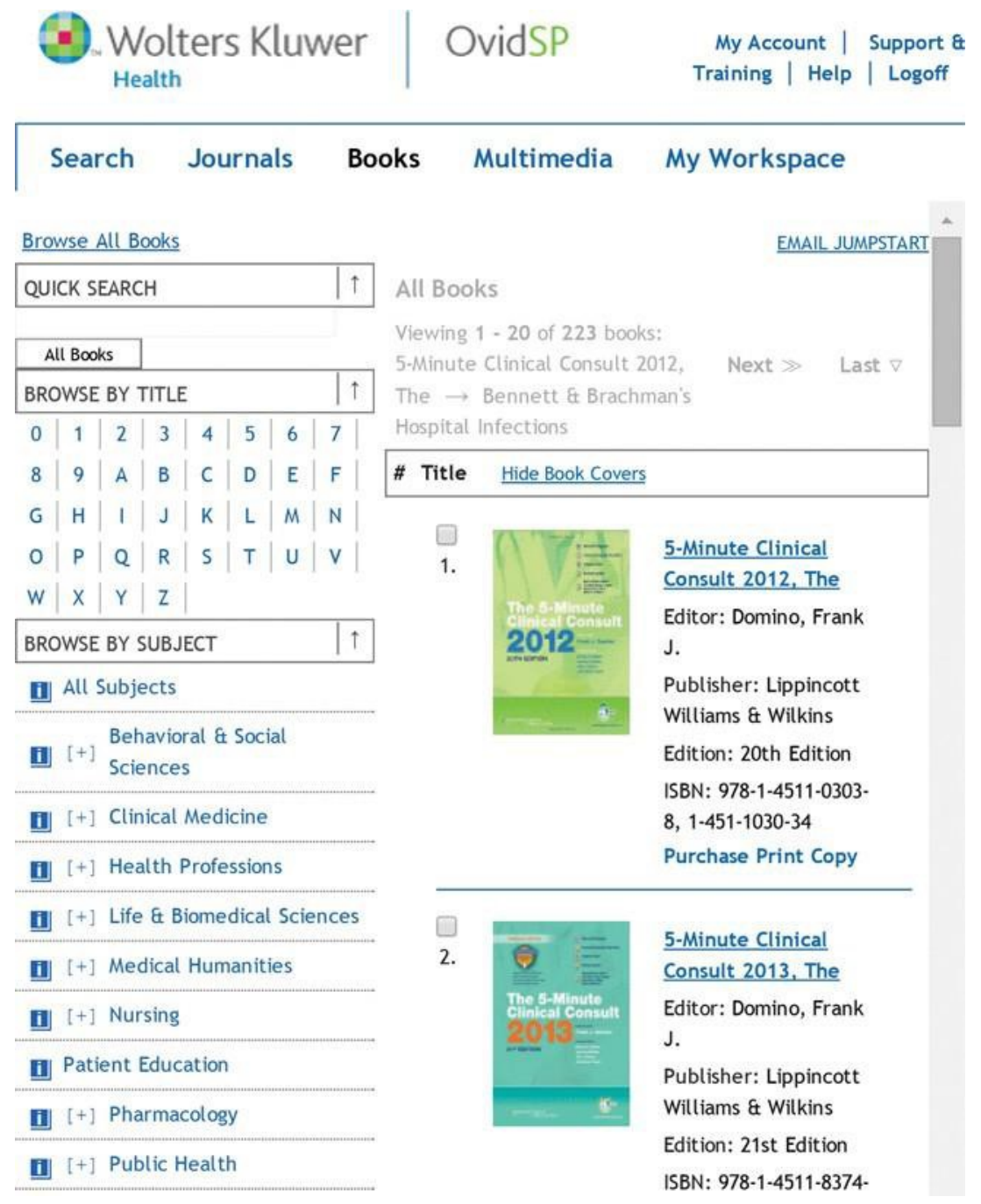

Legend: FIGURE 1. Browse for E-books

Reproduced with permission.

On the browsing screen, the results are organized alphabetically by title, and are presented 20 titles at a time; this number cannot be changed. Overall options include moving to the next page of results or skipping to the last page of the list, emailing a permanent linkor a jumpstart—-to the list of results, or filtering results using the aforementioned browsing options like subject and title filters. Within the list of results, users are presented with each

This is an electronic version of an article published in Ossom Williamson, P. (2015). "A review of OvidSP as an e-books delivery platform,” Journal of Electronic Resources in Medical Libraries, 12(1), 48-58. Journal of Electronic Resources in Medical Libraries is available online at: http://www.tandfonline.com/doi/full/10.1080/15424065.2015.1001963 
book and a link to the full text within the title. The other information available includes the book's editors or authors, publisher, edition, and ISBN. OvidSP also provides an image of the book cover, which can be extremely useful in the case of two books with the same or similar titles and/or authors, or when the cover is the most easily recognizable feature of a book. As a note, clicking the option to hide the book cover images does not increase the number of results displayed per page. Also, for each title users can click Purchase Print Copy to get their own print book.

\section{SEARCHING FOR E-BOOKS}

When providing access to OvidSP, institutions can decide between presenting a list of currently subscribed OvidSP databases and presenting the search interface as a landing page. There are pros and cons to each method. On the one hand, if the user is presented with the search interface immediately, he or she is not given an option to select more or change databases, in cases where another database may be a better option. When this option is selected, institutions are expecting a certain level of database knowledge in their users by assuming that the users know of all the options, how to change or add more databases, and which databases they should use. With this option, users can select more or different databases by clicking Change above the active database’s title. On the other hand, users who must always select a database before being able to enter the resource may feel frustrated that the link to that particular database does not take them directly to it; they have to select Books@Ovid again, as shown in Figure 2.

This is an electronic version of an article published in Ossom Williamson, P. (2015). “A review of OvidSP as an e-books delivery platform,” Journal of Electronic Resources in Medical Libraries, 12(1), 48-58. Journal of Electronic Resources in Medical Libraries is available online at: http://www.tandfonline.com/doi/full/10.1080/15424065.2015.1001963 


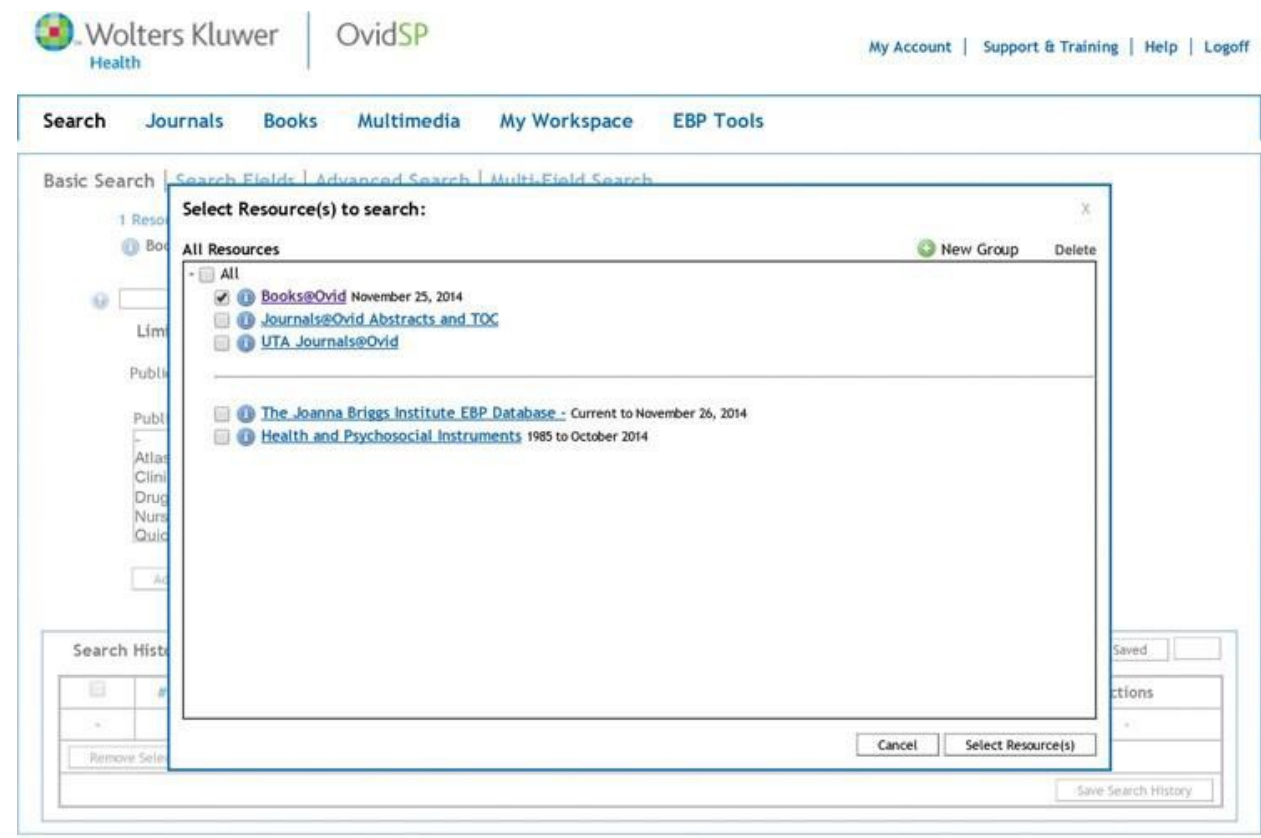

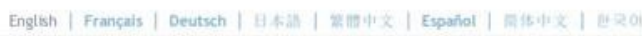

Terms of Use | Support it Training | About Us | Contact us

Version: OvidSP U103.13.01.101, SourcelD 634982

Legend: FIGURE 2. Select a Resource Page

Reproduced with permission.

Ultimately, OvidSP platform defaults on the search interface. Institutions can use the administrative access to retrieve usage statistics and to customize the interface to display one of various search screens as the default search screen. These include the Basic Search, Search Fields, Advanced Search, or Multi-Field Search. Other search options are the Find Citation and Search Tools options. The institution logo can also be added and institutions are able to enable or disable certain options like displaying search limits.

The Find Citation feature allows users to input fields from particular resources they are trying to locate; truncation is automatically selected for names. The Search Tools feature allows users to search within subject headings to look at the hierarchical structure or to search within other areas like scope notes in order to find terms to use in a search.

This is an electronic version of an article published in Ossom Williamson, P. (2015). "A review of OvidSP as an e-books delivery platform,” Journal of Electronic Resources in Medical Libraries, 12(1), 48-58. Journal of Electronic Resources in Medical Libraries is available online at: http://www.tandfonline.com/doi/full/10.1080/15424065.2015.1001963 
Unfortunately, the Find Citation and the Search Tools features can only be used to find journal articles; therefore, they have no use if an institution only has e-book subscriptions through Ovid Technologies, and they do not appear if Books@Ovid is the only database being searched at a moment. If Books@Ovid is selected along with one or more other databases that involve journals, those features will appear but will not be searching Books@Ovid.

Basic Search is customizable but provides one long search bar to allow for both novice users who may want to put in a simple keyword search and experienced searchers who may want to put in longer, already developed search strategies without having to use drop-down menus. The Basic Search feature also allows for various limits including limiting a search by publication year and publication type. Users can also limit to searching within one book’s full text by choosing its title in the drop-down menu next to "Limit to Book.” To increase results, there are options to include multimedia results and to include related terms in the search.

Advanced search is almost exactly the same as basic search; it has a few minor differences. First, users can select Author, Title (which is the chapter title), or Book Name (which is the book title) as the field to search. Second, there are options to Keyword search—which is the default—or to perform a Natural Language Search. The Keyword search option retrieves books with the term in the title, authors' names, abstract, or full text. The Natural Language Search takes what has been input and looks for that term as well as other related terms. For example, when searching for the term ears using Keyword search, the author retrieved 2,034 results, and under Search Information, it listed ears as 
the term searched and ears as the search terms used. When performing the same search using the Natural Language Search, the author retrieved 7,665 results. Under Search Information, it listed ears as the term searched and the following terms were used to retrieve results: ears, ear, vestibulocochlear organ, vestibulocochlear system, vestibulocochlear apparatus, hearing apparatus, ear structure, auris, and ear related structure. This feature can be beneficial for users who are new to searching and are not finding enough results, because the database will add related like-terms to their search.

Search Fields is a screen much different than Basic Search or Advanced Search, see Figure 3. When this option is selected, the user can check mark each field to be searched by the inputted search terms. For example, the user could check the search the Book Editor, Author, and Chapter Author fields if he or she is unsure which title is applicable for the name they are inputting. The final search option is Multi-Field Search. This search is very similar to Basic Search; however, it provides multiple lines with a drop-down of Boolean operators between each line. After each line is a drop-down menu with field options to limit each line's terms to that specific field. Limits are the same in Multi-Field Search as they are in Basic Search and Advanced Search. 


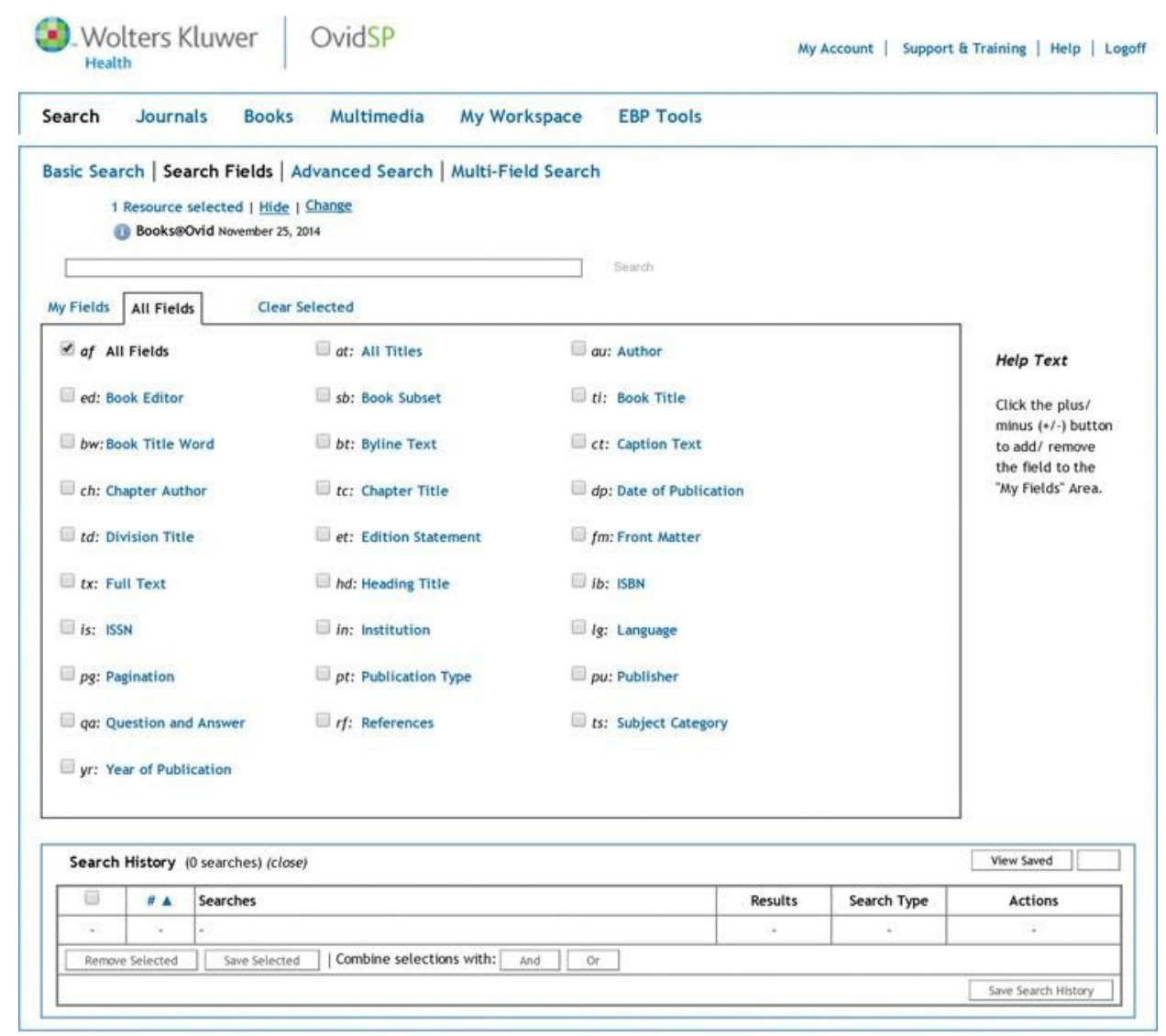

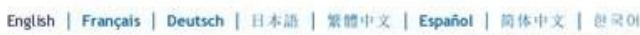

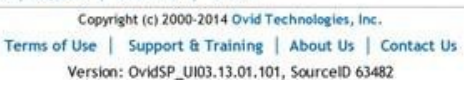

Legend: FIGURE 3. Search Fields Option

Reproduced with permission.

Regardless of any search option, clicking on a field will provide a pop-up window describing that field. Also, truncation symbols * and 1 can be used in any search box. The other feature each search option has in common is the Search History box. The Search History box keeps up with all previous searches and assigns the searches a search number. Search numbers can be combined in order to create a new search. See Figure 4 for an example of combining previous searches.

This is an electronic version of an article published in Ossom Williamson, P. (2015). "A review of OvidSP as an e-books delivery platform,” Journal of Electronic Resources in Medical Libraries, 12(1), 48-58. Journal of Electronic Resources in Medical Libraries is available online at: http://www.tandfonline.com/doi/full/10.1080/15424065.2015.1001963 

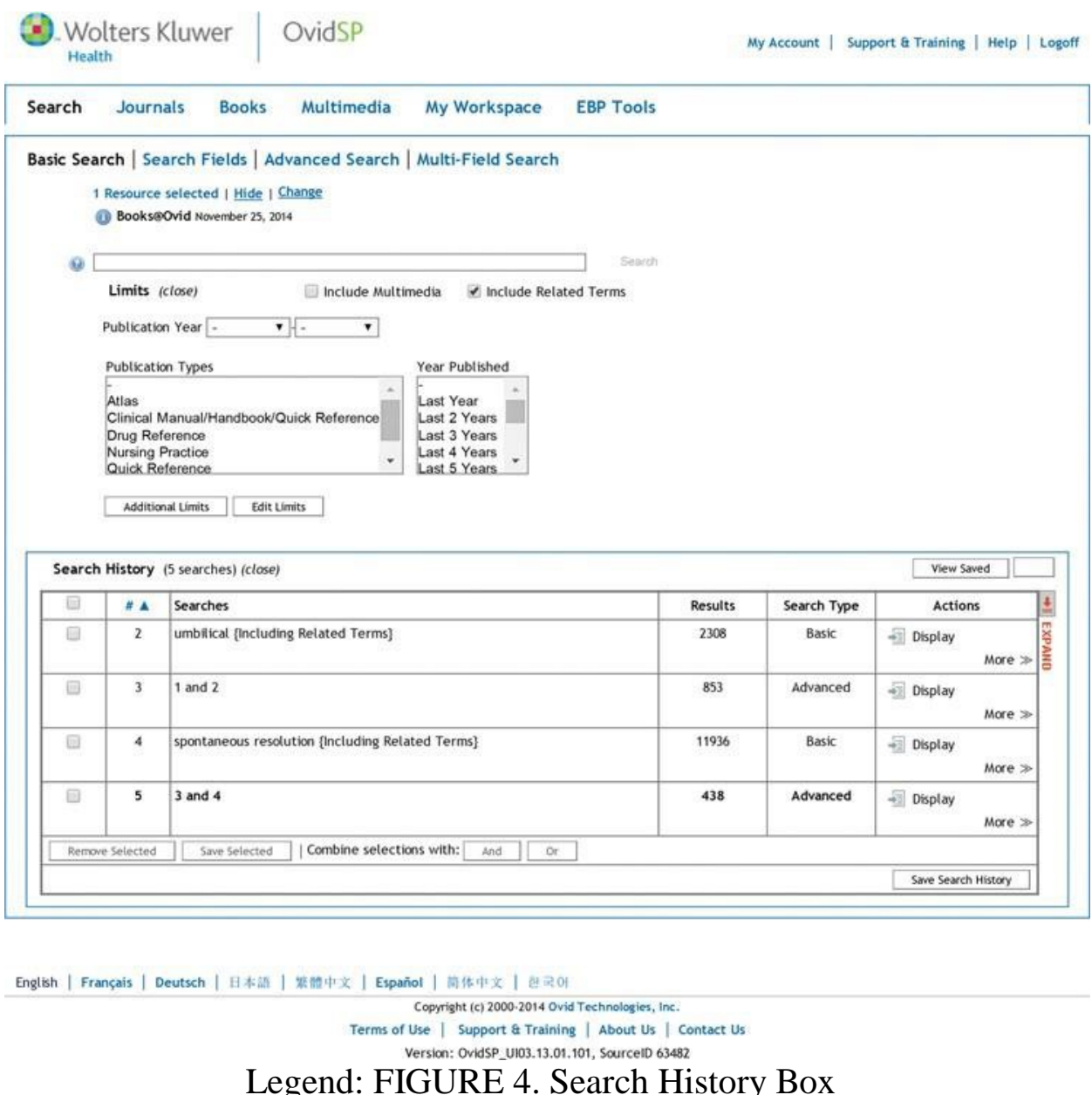

Reproduced with permission.

\section{WORKING WITH RESULTS}

There are many options for users browsing through search results. There are options to print or email citations of the items in the results list, and an option to export citations as Word DOC, Excel XLS, Adobe PDF, RIS, XML, or TXT files and to the more common citation managers like RefWorks and EndNote. If the user would like to create an individual account, these results as well as search strings can be saved for later use. On the left are options to

This is an electronic version of an article published in Ossom Williamson, P. (2015). “A review of OvidSP as an e-books delivery platform,” Journal of Electronic Resources in Medical Libraries, 12(1), 48-58. Journal of Electronic Resources in Medical Libraries is available online at: http://www.tandfonline.com/doi/full/10.1080/15424065.2015.1001963 
view the search terms that were included. Users can also filter results by Publication Year, Publication Type (Text/Reference or Clinical Manual/Handbook/Quick Reference), or Subject/Category. Display options can be adjusted as well. Users can choose to have results displayed as $5,10,25,50$, or 100 results per page and to view just the titles, the citation, or the citation with abstract for the results list. Results are displayed in order of relevance using a star system, where more stars mean more relevance of that resource to the search. For example, when a result has 5 stars, it means that that all query concepts were found within the text; when a result has 3 stars, it means that the result is missing a major query component. This is the method used by OvidSP to determine whether a book is relevant to the searcher; however, it is less precise or accurate than the use of subject headings, which are not present in Books@Ovid.

Finding the full text can be slightly misleading for new users when the link resolver is present within the database. This is due to the link resolver being placed next to the citation information and the lack of wording that explains how full text access is provided through clicking the book or book chapter title. When clicking on a result, the user is taken to the chapter in the e-book that is most relevant according to the search. Terms from the search that were found within the chapter are colored red in order for users to quickly find what they need. The other feature to help pinpoint the most relevant information from the book is the search bar. The search bar is present within the full text interface of each book, and it allows the user to search within the currently opened book or within all books. It also has the option to check for spelling errors. e-books delivery platform,” Journal of Electronic Resources in Medical Libraries, 12(1), 48-58. Journal of Electronic Resources in Medical Libraries is available online at: http://www.tandfonline.com/doi/full/10.1080/15424065.2015.1001963 


\section{READING AND USING E-BOOKS}

This is an electronic version of an article published in Ossom Williamson, P. (2015). "A review of OvidSP as an e-books delivery platform,” Journal of Electronic Resources in Medical Libraries, 12(1), 48-58.

Journal of Electronic Resources in Medical Libraries is available online at:

http://www.tandfonline.com/doi/full/10.1080/15424065.2015.1001963 


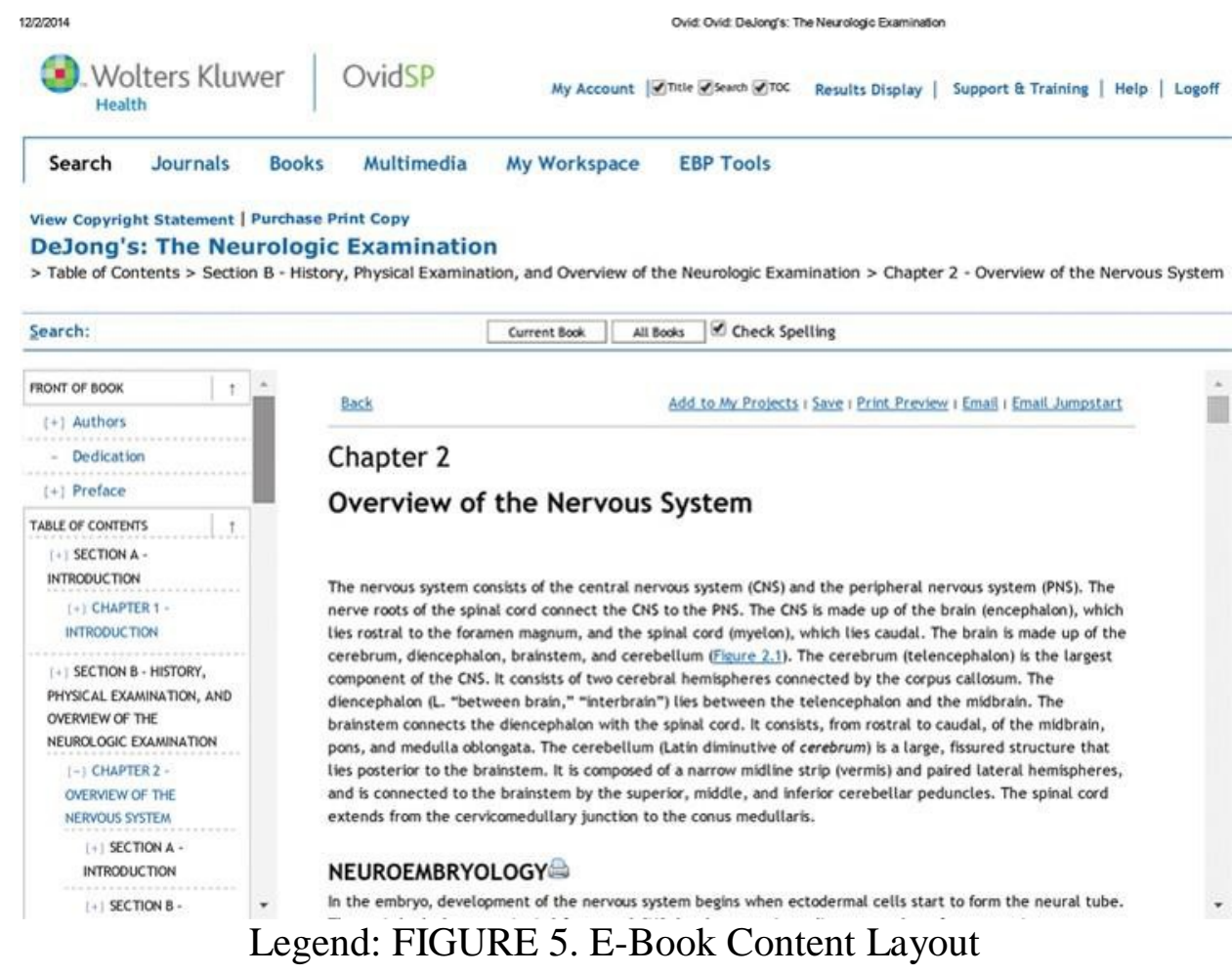

Reproduced with permission.

Each e-book has a menu on the left that displays each part, i.e., Front of Book, Table of Contents, and Back of Book. Within these parts are the book Sections and Chapters. In the main display, one chapter is displayed at a time. Within that content, there is a printer icon next to each section heading in order to make it easy to print small sections from a chapter. Above the chapter, there are options to save the chapter, print the chapter, email the contents of the chapter, or email the jumpstart/link to the chapter. The chapters cannot be saved as a PDF; however, they can be saved as TXT files or as an HTML file. The HTML file is well formatted and includes figures, so a user could change the format by copying the content and pasting it into a Word document or by saving the page as a PDF file.

This is an electronic version of an article published in Ossom Williamson, P. (2015). "A review of OvidSP as an e-books delivery platform,” Journal of Electronic Resources in Medical Libraries, 12(1), 48-58. Journal of Electronic Resources in Medical Libraries is available online at: http://www.tandfonline.com/doi/full/10.1080/15424065.2015.1001963 


\section{CONCLUSION}

The Books@Ovid database has many strengths. It provides a plethora of content that is relevant to health care employees in hospitals, clinics, and offices, as well as for students of medical, nursing, dental, and allied health programs. Also advantageous are the options to choose from a variety of publishers and to subscribe to collections as well as individual titles in order to have a collection as robust as is necessary for a particular institution's needs.

The OvidSP platform also incorporates other databases that come within its interface, and works will with simple natural language or keyword searching. This is beneficial for the practitioner looking to quickly find relevant content or for an inexperienced searcher. In addition, there are many options for searching which allows users to choose which search method they prefer.

Consequently, major weaknesses of OvidSP are the confusing manner with which many of these options are laid out. Browsing options are organized well, but the searching options can be difficult to understand. There are also many options that are present on the two most common pages, Basic Search and Advanced Search, which users are likely to never use. In some ways, the interface was created for novice users: The search bar was simplified and subject headings were not included. However, there are a plethora of limiters and methods of searching using a mix of keywords and limiters that must be done using abbreviations, which is not user friendly. Lastly, the lack of PDFs make saving content in a format that is preferred by most users much more difficult than if PDFs were provided. 
Overall, it is very beneficial for institutions to subscribe to e-books through Ovid Technologies, Inc.’ Books@Ovid database, and this is especially true for institutions that subscribe to many other resources through OvidSP because of the unified searching abilities. Because of the strength of the content, customizability, and searching abilities, OvidSP can be a great asset for providing online access to important resources.

\section{REFERENCES}

1. Ovid Technologies, Inc. 2014. “Books on Ovid.’’ Available: <http://www.ovid. com/site/catalog/books/index.jsp>. Accessed: October 5, 2014.

2. Herold, B. "Survey: Students’ Mobile-Device Use Rising.' Education Week 34(September 17, 2014). 5. Available: http://www.edweek.org/ew/articles/2014/ 09/17/04report-b1.h34.html. Accessed: October 11, 2014.

3. Wolverton, R.E., and Davidson, K. "Information Use and Mobile Devices in Medicine: A Multi-University Study.” Journal of Electronic Resources Librarian- ship 25(March 11, 2013). 73. Available: http://www.tandfonline.com.ezproxy. uta.edu/doi/full/10.1080/1941126X.2013.761548. Accessed: October 11, 2014. 